\title{
Addressing the "shadow pandemic" through a public health approach to violence prevention
}

\author{
Lara C. Snowdon, Emma R. Barton,* Annemarie Newbury, ${ }^{*}$ Bryony Parry, ${ }^{*}$ Mark A. Bellis, \\ and Joanne C. Hopkins*
}

\begin{abstract}
Experts from across the globe have warned of the adverse consequences of COVID-19 lockdown and physical distancing restrictions on violence in the home, with the United Nations describing it as a shadow pandemic. This social innovation narrative explores how a public health approach to violence prevention is implemented in Wales during the COVID-19 pandemic by the multi-agency Wales Violence Prevention Unit. The article highlights early trends in monitoring data on the impact of COVID-19 restrictions on violence, including likely increases in domestic and sexual violence and abuse, concerns over the safety of children and young people, both online and in the home, and increased reporting of elder abuse. The article supports the notion of a shadow pandemic, emphasizing the lack of data that routinely measures violence in the home and online that disproportionately affects women, children, and older people, as well as vulnerable and minority populations. This renders these forms of violence much less "visible" to policy-makers in comparison with violence in public spaces, but they are of no less public health significance. Through sharing this narrative and early findings, we call for increased focus on the development of new data collection methods and violence prevention programs during the COVID-19 pandemic and in the future.
\end{abstract}

Key Words Policing; partnerships; emergency services; multi-agency approach; data analysis; data-led practice.

\section{INTRODUCTION}

The impact of lockdown measures on violence has been described by the United Nations (UN News, 2020) as a shadow pandemic, with calls for a "ceasefire" in people's homes from Secretary-General António Guterres. Internationally, news outlets, governments, and non-governmental organizations have widely reported on surges in demand for domestic abuse helplines (UN News, 2020), concerns over online safety (Internet Watch Foundation, 2020), stalking, and harassment (Paladin National Stalking Advocacy Service, 2020), and increases in adverse childhood experiences (NSPCC, 2020), with experts voicing concern that the conditions of lockdown magnify existing violent and abusive behaviour and create new risks.

This social innovation narrative explores how the newly established Wales Violence Prevention Unit (VPU) is taking a public health approach to preventing violence during the pandemic, referencing how the team has capitalized on an extensive history of partnership between policing and public health. We also discuss the emerging literature on COVID-19 and violence, explore trends in monitoring data, and indicate how this approach, developed by the Wales VPU, adds to the global evidence base.

\section{COVID-19 and Violence}

There is a rapidly emerging literature on the association between violence and infectious disease restrictions, as researchers, frontline professionals, and policy makers begin to comprehend the social and health implications of restrictions enforced by governments across the globe in response to the COVID-19 pandemic. There are strong indications that population levels of interpersonal violence have increased within intimate partner, familial, and carer relationships, as well as violence and abuse online, with a profound impact for children, adults, and families. Concurrently, violence within public spaces, including the night-time economy, has reduced as people are encouraged to stay at home.

Whilst causation of violence is multi-factorial (Krug et al., 2002), it is apparent that pandemic restrictions have heightened the risk of violence, especially in the home and online, exacerbating the behaviour of perpetrators, and decreasing

Correspondence to: Lara C. Snowdon, Violence Prevention Program Lead, World Health Organization Collaborating Centre for Investment in Health and Wellbeing,
Public Health Wales, 2 Capital Quarter, Tyndall Street, Cardiff, United Kingdom. E-mail: lara.snowdon@wales.nhs.uk
To cite: Snowdon, L. C., Barton, E. R., Newbury, A. Parry, B., Bellis, M.A., and Hopkins, J.C. (2020). Addressing the "shadow pandemic" through a public health ap-
proach to violence prevention. Journal of Community Safety and Well-Being, 5(2), 60-65. https://doi.org/10.35502/icswb.141
(C) Author(s) 2020. Open Access. This work is distributed under the Creative Commons BY-NC-ND license. For commercial re-use, please contact sales@sgpublishing.ca. g.PUBLISHING Published by SG Publishing Inc. CSKA Official publication of the Community Safety Knowledge Alliance. 
the ability of victims to access support (see Figure 1). Risk factors discussed in the emerging literature on COVID-19 and violence include: quarantine and social isolation, stress, anxiety, and mental health issues, changes to working patterns and loss of employment, alcohol and drug abuse (Gunnell et al., 2020), weak institutional responses (Walton \& Falkner, 2020), and reinforcement of traditional gender roles (Blaskó et al., 2020). Concurrently, there is a loss of access to protective factors such as schools, access to friends, extended family, the workplace, and other support mechanisms (Social Care Institute for Excellence, 2020).

Further to this, the social, economic, and health impacts of lockdown measures have not been distributed evenly across populations. As Ahmed, Ahmed, Pissarides, \& Stiglitz (2020) advise in their commentary in The Lancet, "pandemics rarely affect all people in a uniform way." Violence is no exception to this rule, with women, children and young people, older people, and those who are socially-isolated and/or vulnerable at a higher risk of victimization, as the risk of violence moves out of public spaces into the home.

The contextual and changing nature of restriction measures mean that trends in violence will likely be dynamic as social rules are enforced or relaxed. Considering the longer-term implications for violence when public health measures are lifted, particularly if there are considerable social and economic changes that increase unemployment, poverty, and inequality, is of critical importance. For example, it's likely that we will see increases in interpersonal violence in the night-time economy as bars and pubs reopen, and there may be changes to patterns of collective violence such as civil tension, unrest, hate crime, violent extremism and conflict, and violence and exploitation from serious organized crime groups as a "new normal" emerges.

\section{Wales Violence Prevention Unit}

The Wales Violence Prevention Unit (VPU) is a partnership of people from an alliance of organizations working together to prevent all forms of violence in Wales. Established through funding from the Home Office in 2019, the core team comprises members from the four police forces across Wales, the South Wales Police and Crime Commissioner, Public Health Wales (PHW), Her Majesty's Prison and Probation Service

\footnotetext{
- Social isolation and quarantine measures

- Mental health concerns including stress and anxiety

- Loss of income, unemployment, financial insecurity

- Alcohol and drug abuse

- Reinforcement of traditional gender roles

- Weak institutional responses

- Socio-economic vulnerability

Concurrent loss of protective factors:

- Closure of workplaces, schools, places of worship

- Decreased access to support services

- Decreased access to friends, family and colleagues

FIGURE 1 Emerging risk factors for COVID-19-related violence
}

(HMPPS), Home Office Immigration and representatives from the voluntary sector (Wales Violence Prevention Unit, 2020). The Wales VPU is one of eighteen similar violence prevention units established across England and Wales in 2019.

The Wales VPU has adopted the World Health Organization (2020) public health approach to violence prevention. This approach uses the principles of public health as a framework for investigating and understanding the causes and consequences of violence and preventing violence through evidence-based prevention programs, policy, and advocacy. The approach emphasizes the importance of a multi-agency partnership and the value that the collective expertise of partners can bring to the table. Through this approach, the VPU aims to develop a wholesystem response to preventing all forms of violence in Wales.

\section{Police and Public Health Partnerships in Wales}

The development and launch of the Wales VPU rests on a long history of police and public health partnership with a focus on addressing vulnerability and the root causes of violence and crime. Numerous programs and policies such as the Adverse Childhood Experience (ACE) Hub (ACE Support Hub Cymru, 2020), the Early Action Together Program (2020), the Cardiff Model (Crime and Security Research Institute, 2020), South Wales Violence Surveillance System (VSS) (Barton et al., 2016), and the Welsh Government Future Generations Act (Welsh Government, 2015) have all built the international case for police and public health partnership through a traumainformed and child-centred lens.

The governance, relationships and approaches that have been jointly developed through these innovative programs have equipped policing in Wales with the tools to adapt to the changing demands of modern policing and, likewise, ensured that public health professionals are able to "keep a finger on the pulse" of policing and emergency service demand in order to understand and address underlying vulnerability. The Wales VPU builds on this history of partnership and has been able to adapt the system in response to changing demand relating to the COVID-19 pandemic and restriction measures.

\section{Implementing a public health approach to violence prevention during COVID-19}

As a focused, multi-agency unit supported by a team of public health analysts, the Wales VPU is in a unique position to provide knowledge, capacity, and capability to support the violence prevention and response measures of partners and stakeholders. Building on a solid foundation of partnership working, the VPU's strategic approach to violence prevention during the COVID-19 pandemic is focused on four strands of action:

\section{Data analysis}

The Wales VPU brings partnership data together through weekly monitoring reports. These reports analyze and monitor all forms of violence to identify trends, patterns, and hotspots emerging during the crisis. This "real time" violence surveillance enables partners (such as the Welsh Government, policing, HMPPS, and voluntary sector partners) to initiate data-led prevention and response measures both now and when public health measures are lifted, as well as adding to the evidence base for future events. 


\section{Strategic communications}

The Wales VPU works with partners to shape and align evidence-informed communications. As a multi-agency team, we are in a unique position to identify opportunities and gaps, share strategic intelligence, and ensure that partners have the most up-to-date knowledge and evidence to inform their communications.

\section{Supporting frontline services}

The Wales VPU is uniquely placed to listen to our partners and provide support, advocacy, and information to frontline services. For services commissioned by the VPU, most intervention work has moved online, with providers working tirelessly to prevent violence and protect those at risk.

\section{Information, guidance and evidence}

The Wales VPU acts as an information hub for guidance, information, research, and evidence relating to violence prevention. Through our website, regular e-Bulletins, and partnership working, the VPU is able to share information, resources, and guidance with partners to inform evidence-based practice.

\section{Violence and COVID-19: emerging trends in Wales and the United Kingdom}

The Wales VPU violence and COVID-19 weekly monitoring reports collate and analyze data from a range of partners. Data sources include: police data, accident and emergency department (A\&E) data, helpline and service demand data from voluntary sector partners, a weekly monitoring survey for professionals, media reports, and data from the Public Health Wales (2020) national engagement survey on health and well-being. Table I shows an overview of the data sources used within the Wales VPU violence and COVID-19 monitoring reports and highlights a number of emerging trends. Intelligence gathered to date supports the idea that those already vulnerable are at greater risk of violence and abuse as a result of COVID-19 restrictions. Whilst it is too early to draw conclusions, here we discuss some of the early trends emerging from the data:

\section{Violence against women and girls and domestic and sexual violence and abuse}

Professionals have routinely expressed concern over the risk lockdown measures pose to domestic abuse victims, with restrictions exacerbating existing abusive behaviour by perpetrators. Wales has seen a mixed picture regarding reporting of domestic abuse to emergency services and the Welsh domestic abuse helpline (managed by Welsh Women's Aid), which both saw an initial decrease, followed by a gradual return to prelockdown levels (Table II). This was in stark opposition to the English domestic abuse helpline, which saw an initial significant increase in calls and website visits, and CrimeStoppers (a UK-wide charity for anonymous reporting of crime) reported a significant increase in calls relating to domestic abuse from the beginning of UK lockdown measures. This raised concerns of underreporting and lack of opportunity to report in Wales.

However, in recent weeks as lockdown has been extended and the Welsh Government and partners have implemented a communications campaign with the aim of increasing reporting, both police reports and Welsh domestic abuse helpline calls have begun to increase and now resemble pre-lockdown demand (Table II). South Wales' Health Board data also reflects this steady increase in reporting. Since A\&E domestic abuse assault attendances remain similar to pre-lockdown figures despite an overall drop in all assaultrelated attendances, domestic abuse A\&E attendances now reflect a greater proportion of those requiring medical attention because of violence (Table II). Welsh Women's Aid also report increased severity and complexity of abuse, anxiety and mental health issues among their service users.

The UK Report Harmful Content (RHC) helpline (for 13 years and above) reports a significant increase in cases and website visits, and a week-on-week rise in reports since lockdown began (Table III), with the vast majority of cases from women. The most common concerns include: coercive control, domestic abuse, harassment, intimate image abuse, and stalking. Calls to the UK Revenge Porn Helpline (for adults) almost doubled in April 2020 compared with the same period in 2019, with a significant rise in calls regarding sextortion. Traditionally, this would be male victims, but the last month (April 2020) has seen a rise in the number of female victims. Concerns are now being raised by professionals over increases in sexual violence as lockdown measures are gradually lifted and the night-time economy reopens.

\section{Children and young people}

During childhood, we are especially vulnerable to the main determinants of health: living conditions, family income, employment, education, and access to health services. Global modelling predicts a stark increase in child mortality as a result of diversion of healthcare to adults with COVID-19 (Sinha et al., 2020). We know that infection and mortality rates are higher in areas of higher deprivation; children in these areas will also be impacted by food insecurity, poor-quality housing, no access to outside space or to electronic devices or internet.

Our analysis raises a number of concerns regarding children and young people experiencing violence during lockdown restrictions. The likely increase in domestic violence and abuse indicates that children and young people will be experiencing this in the home, with less opportunities to have the support of friends, extended family, schools, and other protective mechanisms (Social Care Institute for Excellence, 2020). Further data indicates a possible increase in adverse childhood experiences, including the National Society for the Prevention of Cruelty to Children (NSPCC) reporting that "parent/adult health/behaviour" is the most common category of report to their helpline for children and, within that, "parental alcohol/substance misuse" the most common sub-concern.

Child abuse and neglect experienced in the home is also a concern, with restriction measures exacerbating the behaviour of abusive adults. The NSPCC reports a large increase in both the number and overall proportion of counselling sessions about emotional abuse of children, and a significant increase in calls from adults regarding concerns about a child relating to neglect, physical abuse, and emotional abuse (Table IV).

As with adults, reports of child sexual abuse and exploitation (CSAE) online is an area of high concern (BBC, 2020). NSPCC helplines have seen a large increase in child welfare contacts where Coronavirus was mentioned specifically in relation to sexual abuse online. The Internet Watch Foundation (2020) reports that it has blocked millions of 
attempts to download child sexual abuse imagery online during lockdown and the UK's National Crime Agency is investigating more than 120 cases of "Zoombombing" with child abuse imagery. It appears highly likely that online CSAE is increasing amidst less opportunities to report offences, increased time online by both victims and perpetrators, and children experiencing abuse less likely to be recognized by peers, teachers, and others in the community who would previously have provided support and reported incidents (Social Care Institute for Excellence, 2020).

TABLE I Wales VPU violence and COVID-19 weekly monitoring report data sources

\begin{tabular}{|c|c|c|c|c|c|c|}
\hline Violence Type & Data Sources & $\begin{array}{l}\text { Frequency of } \\
\text { Data Received }\end{array}$ & $\begin{array}{l}\text { Demand Immediately } \\
\text { Post-Lockdown }\end{array}$ & & $\begin{array}{l}\text { Demand } 2 \text { Months } \\
\text { Post-Lockdown }\end{array}$ & \\
\hline \multirow{5}{*}{$\begin{array}{l}\text { Domestic } \\
\text { violence } \\
\text { and abuse }\end{array}$} & $\begin{array}{l}\text { Four Welsh Police Forces [Dyfed Powys, } \\
\text { Gwent, North Wales, South Wales] }\end{array}$ & Weekly & Decrease & $\downarrow$ & $\begin{array}{l}\text { Increased - now similar to } \\
\text { pre-lockdown levels }\end{array}$ & $\uparrow$ \\
\hline & $\begin{array}{l}\text { Welsh Women's Aid } \\
\text { [Live Fear Free helpline] }\end{array}$ & Weekly & Decrease & $\downarrow$ & $\begin{array}{l}\text { Increased and stabilised - now } \\
\text { similar to pre-lockdown levels }\end{array}$ & $\uparrow$ \\
\hline & $\begin{array}{c}\text { Refuge } \\
\text { [national domestic abuse helpline] }\end{array}$ & Once & Increase & $\uparrow$ & Increase & $\uparrow$ \\
\hline & CrimeStoppers & Weekly & Increase & $\uparrow$ & Increase & $\uparrow$ \\
\hline & South Wales' Health Board data & Monthly & $\begin{array}{l}\text { Held at 'normal' levels } \\
\text { despite overall decrease }\end{array}$ & $=$ & $\begin{array}{l}\text { Held at 'normal' levels } \\
\text { despite overall decrease }\end{array}$ & $=$ \\
\hline \multirow{3}{*}{$\begin{array}{l}\text { Sexual violence } \\
\text { and abuse }\end{array}$} & South Wales Police Force & Weekly & Decrease & $\downarrow$ & $\begin{array}{l}\text { Increased - now similar to } \\
\text { pre-lockdown levels }\end{array}$ & $\uparrow$ \\
\hline & Report Harmful Content Helpline & Bi-monthly & Increase & $\uparrow$ & Increase & $\uparrow$ \\
\hline & UK Revenge Porn Helpline & Bi-monthly & Increase & $\uparrow$ & Increase & $\uparrow$ \\
\hline \multirow{4}{*}{$\begin{array}{l}\text { Child abuse } \\
\text { and sexual } \\
\text { exploitation }\end{array}$} & $\begin{array}{c}\text { Tarian ROCU [Regional Organised } \\
\text { Crime Unit] }\end{array}$ & Weekly & $\begin{array}{c}\text { Increase } \\
\text { [IIOC online offences] }\end{array}$ & $\uparrow$ & $\begin{array}{c}\text { Increase [IIOC online offences] } \\
\text { - demand fluctuates } \\
\text { week on week }\end{array}$ & $\uparrow$ \\
\hline & & & Decrease [CSA] & $\downarrow$ & Decrease [CSA] & $\downarrow$ \\
\hline & $\begin{array}{c}\text { Childline [adult and professionals } \\
\text { helpline] }\end{array}$ & Weekly & Increase & $\uparrow$ & Increase & $\uparrow$ \\
\hline & NSPCC [adult concerns] & Weekly & Increase & $\uparrow$ & Increase & $\uparrow$ \\
\hline Elder abuse & Hourglass [UK national charity] & Monthly & Increase & $\uparrow$ & Increase & 1 \\
\hline \multirow{2}{*}{$\begin{array}{l}\text { Night-time } \\
\text { economy }\end{array}$} & South Wales Police Force & Monthly & Decrease & $\downarrow$ & Decrease & $\downarrow$ \\
\hline & South Wales' Health Board data & Monthly & Decrease & $\downarrow$ & Decrease & $\downarrow$ \\
\hline
\end{tabular}

VPU = violence protection unit; DA = domestic abuse; NSPCC = National Society for the Prevention of Cruelty to Children; $\| O C=$ indecent images of children; CSA = child sexual abuse.

TABLE II Domestic violence and abuse data sources

\begin{tabular}{|c|c|c|c|c|c|c|}
\hline Violence Type & Data Sources & $\begin{array}{l}\text { Frequency of } \\
\text { Data Received }\end{array}$ & $\begin{array}{l}\text { Demand Immediately } \\
\text { Post-Lockdown }\end{array}$ & & $\begin{array}{l}\text { Demand } 2 \text { Months } \\
\text { Post-Lockdown }\end{array}$ & \\
\hline \multirow{5}{*}{$\begin{array}{l}\text { Domestic } \\
\text { violence } \\
\text { and abuse }\end{array}$} & $\begin{array}{c}\text { Four Welsh Police Forces } \\
\text { [Dyfed Powys, Gwent, North Wales, } \\
\text { South Wales] }\end{array}$ & Weekly & Decrease & $\downarrow$ & $\begin{array}{l}\text { Increased - now similar } \\
\text { to pre-lockdown levels }\end{array}$ & $\uparrow$ \\
\hline & $\begin{array}{l}\text { Welsh Women's Aid } \\
\text { [Live Fear Free helpline] }\end{array}$ & Weekly & Decrease & $\downarrow$ & $\begin{array}{l}\text { Increased and stabilised - } \\
\text { now similar to pre-lockdown } \\
\text { levels }\end{array}$ & $\uparrow$ \\
\hline & $\begin{array}{c}\text { Refuge } \\
\text { [national domestic abuse helpline] }\end{array}$ & Once & Increase & $\uparrow$ & Increase & $\uparrow$ \\
\hline & CrimeStoppers & Weekly & Increase & $\uparrow$ & Increase & $\uparrow$ \\
\hline & South Wales' Health Board data & Monthly & $\begin{array}{l}\text { Held at 'normal' levels } \\
\text { despite overall decrease }\end{array}$ & $=$ & $\begin{array}{l}\text { Held at 'normal' levels } \\
\text { despite overall decrease }\end{array}$ & $=$ \\
\hline
\end{tabular}

$\mathrm{DA}=$ domestic abuse 
TABLE III Sexual violence and abuse data sources

\begin{tabular}{lccccc}
\hline Violence Type & Data Sources & $\begin{array}{c}\text { Frequency of } \\
\text { Data Received }\end{array}$ & $\begin{array}{c}\text { Demand Immediately } \\
\text { Post-Lockdown }\end{array}$ & $\begin{array}{c}\text { Demand 2 Months } \\
\text { Post-Lockdown }\end{array}$ \\
\hline & South Wales Police Force & Weekly & Decrease & $\downarrow$ & $\begin{array}{c}\text { Increased - now similar } \\
\text { to pre-lockdown levels }\end{array}$ \\
$\begin{array}{l}\text { Sexual violence } \\
\text { and abuse }\end{array}$ & Report Harmful Content Helpline & Bi-monthly & Increase & $\uparrow$ & Increase \\
& UK Revenge Porn Helpline & Bi-monthly & Increase & $\uparrow$ & Increase \\
\hline
\end{tabular}

TABLE IV Child abuse and sexual exploitation data sources

\begin{tabular}{|c|c|c|c|c|c|c|}
\hline Violence Type & Data Sources & $\begin{array}{l}\text { Frequency of } \\
\text { Data Received }\end{array}$ & $\begin{array}{l}\text { Demand Immediately } \\
\text { Post-Lockdown }\end{array}$ & & $\begin{array}{l}\text { Demand } 2 \text { Months } \\
\text { Post-Lockdown }\end{array}$ & \\
\hline \multirow{4}{*}{$\begin{array}{l}\text { Child abuse } \\
\text { and sexual exploi- } \\
\text { tation }\end{array}$} & $\begin{array}{c}\text { Tarian ROCU } \\
\text { [Regional Organised Crime Unit] }\end{array}$ & Weekly & $\begin{array}{c}\text { Increase } \\
\text { [IIOC online offences] }\end{array}$ & $\uparrow$ & $\begin{array}{c}\text { Increase [IIOC online } \\
\text { offences] - demand } \\
\text { fluctuates week on week }\end{array}$ & $\uparrow$ \\
\hline & & & Decrease [CSA] & $\downarrow$ & Decrease $[\mathrm{CSA}]$ & $\downarrow$ \\
\hline & $\begin{array}{c}\text { Childline } \\
\text { [adult and professional helpline] }\end{array}$ & Weekly & Increase & $\uparrow$ & Increase & $\uparrow$ \\
\hline & NSPCC [adult concerns] & Weekly & Increase & $\uparrow$ & Increase & $\uparrow$ \\
\hline
\end{tabular}

$\| O C=$ indecent images of children; CSA = child sexual abuse; NSPCC = National Society for the Prevention of Cruelty to Children.

\section{Elder abuse}

There is concern that criminals are using the current situation to abuse and defraud people, specifically targeting older people due to their perceived vulnerability; and lockdown conditions have exacerbated and further isolated older people in abusive relationships with spouses, families, or carers. Hourglass, a UK national charity tackling harm and abuse of older people, has seen a $34 \%$ increase in calls to their helpline since lockdown began (Table I). An increase in callers reporting psychological, financial, and physical abuse related to the impact of lockdown and COVID-19 response has been noted.

\section{DISCUSSION}

Internationally, the violence-related consequences of the COVID-19 pandemic restrictions are likely to vary depending on countries' public health control measures, sociocultural and demographic structures, and existing welfare supports. Despite a gradual lifting of lockdown measures in Europe and North America, a second wave of the pandemic or other infectious diseases could resurface at any time. People can live with the devastating consequences of violence for many years, not just during the outbreak itself. As such, unless robust response and prevention measures are established, second peaks or new infections will be met with even greater chronic and sustained stress to those affected by violence.

Critically, the context of COVID-19 has created an opportunity to look more at the violence that happens in people's homes and online and not just at the more visible violence in public spaces, including the night-time economy. Measuring violence during the COVID-19 pandemic highlights a lack of data on violence experienced in the home and in "private" spaces (including online) that disproportionately affects women, children, and older people, as well as vulnerable and minority populations. Available data measuring forms of vio- lence experienced by these groups is both less accessible and less frequently collected. Monitoring data on violence during COVID-19 restrictions only amplifies this and supports the notion of a "shadow pandemic" that may be less visible but is of no less public health significance.

Developing new and innovative data collection methods and violence prevention programs, such as whole-system approaches, building community resilience, and empowering bystanders, including neighbours, friends, family, and the community, is of critical importance. This will ensure that the global violence prevention community can learn how to cope with other pandemics and crises, but we should also emerge better equipped to deal with the abuse and neglect that happens in people's homes and online, whether there is a pandemic or not.

Contributing to a global conversation and sharing learning, research, and ideas, is of utmost importance to develop this system change and growth. We hope that, by sharing this narrative of the work in Wales, we can help to better define the public health role in violence prevention, emphasize the importance of multi-agency teams working together to prevent violence, and highlight the importance of monitoring the impact of COVID-19 restrictions on violence. This will produce a more resilient system that is able to prevent violence both during the pandemic and in the future.

\section{CONCLUSION}

Repeated calls from global bodies, the media, victims, and professionals have warned of the adverse consequences of COVID-19 lockdown restrictions on violence. This social innovation narrative explores how a public health approach is implemented to monitor trends in violence and inform violence prevention activity in Wales during the pandemic. Based on early trends from this data, specific concerns are 
identified including likely increases in domestic and sexual violence and abuse, concerns about the safety of children and young people both online and in the home, and concerns around increased reporting of elder abuse. The article addresses the lack of data that routinely measures violence online and in people's homes and discusses the opportunity that the pandemic has created to focus on these forms of violence and develop new data collection methods and prevention programs. In conclusion, the collaborative role of public health, criminal justice, and voluntary sector partners is emphasized, to prevent violence during the COVID-19 pandemic and in the future.

\section{ACKNOWLEDGEMENTS}

The Wales Violence Prevention Unit receives support in the form of funding from the UK Home Office, and funding in kind from Public Health Wales, the South Wales Police and Crime Commissioner, Her Majesty's Prison and Probation Service, Home Office Immigration, the Welsh Government, and South Wales Police. We are grateful to all our colleagues in the Wales Violence Prevention Unit and Public Health Wales who have developed and implemented this innovative work to prevent violence in Wales. Sincere thanks go to our colleagues and partners in the Welsh Government, the emergency services, and the voluntary sector, including South Wales Health Board, Tarian Regional Organized Crime Unit, Welsh Women's Aid, Refuge, South West Grid for Learning, CrimeStoppers, National Society for the Prevention of Cruelty to Children, Hourglass, and the four Welsh Police Forces-Dyfed Powys Police, Gwent Police, North Wales Police, and South Wales Police-for sharing their data, intelligence, and expertise with us to monitor and prevent violence.

\section{CONFLICT OF INTEREST DISCLOSURES}

The authors have no conflicts of interest to declare.

\section{AUTHOR AFFILIATIONS}

*World Health Organization Collaborating Centre for Investment in Health and Wellbeing, Public Health Wales, Cardiff, United Kingdom.

\section{REFERENCES}

ACE Support Hub Cymru. (2020). ACE Aware Wales. Retrieved from: https://www.aceawarewales.com/welcome

Ahmed, F., Ahmed, N., Pissarides, C., \& Stiglitz, J. (2020). Why inequality could spread COVID-19. The Lancet Public Health, 5(5). Retrieved from: https://www.thelancet.com/journals/ lanpub/article/PIIS2468-2667/20/30085-2/fulltext? utm_ campaign =t|coronavirus2Outm_source $=$ twitterutm_medium $=$ social

Barton, E. R., Long, S. J., \& Roderick, J. (2016). Developing a routine surveillance and analysis system for early intervention and prevention of violence: a multi-agency perspective. Retrieved from: http://www.wales.nhs.uk/sitesplus/documents/888/5.\%20 EmmaBarton\%5FPoster\%5FDeveloping\%20a\%20routine\%20 surveillance $\% 20$ and $\% 20$ analysis\%20system $\% 20$ for $\% 20$ EIP\%20 of\%20violence.pdf

BBC. (2020, May). Online child abuse rising during lockdown warn police. Retrieved from: https://www.bbc.co.uk/news/world-52773344

Blaskó, Z., Papadimitriou, E., \& Manca, A. R. (2020). How will the COVID-19 crisis affect existing gender divides in Europe? Retrieved from: https://publications.jrc.ec.europa.eu/repository/bitstream/ JRC120525/covid_gender_effects_f.pdf

Crime and Security Research Institute. (2020). The CardiffModel. Retrieved from: https://www.cardiff.ac.uk/crime-security-research-institute/ publications/research-briefings/the-cardiff-model

Gunnell, D., Appleby, L., Arensman, E., Hawton, K., John, A., Kapur, N., Khan, M., O'Connor, R. C., Pirkis, J., \& The COVID-19 Suicide Prevention Research Collaboration. (2020). Suicide risk and prevention during the COVID-19 pandemic. The Lancet Psychiatry, 7(6), 468-471. Retrieved from: https://www.thelancet.com/journals/ lanpsy/article/PIIS2215-0366(20)30171-1/fulltext

Internet Watch Foundation. (2020, May 20). Millions of attempts to access child sexual abuse online during lockdown. Retrieved from: https://www.iwf.org.uk/news/millions-of-attempts-to-access-childsexual-abuse-online-during-lockdown

Krug, E. G., Mercy, J., Dahlberg, L., \& Zwi, A. (2002). The world report on violence and health. The Lancet, 5(360), 1083-1088. Retrieved from: https://www.who.int/violence_injury_prevention/violence/ world_report/en/

NSPCC. (2020, April 17). Childline provides lifeline to thousands of children during coronavirus lockdown. Retrieved from: https:// www.nspcc.org.uk/what-we-do/news-opinion/childline-lifelinecoronavirus/

Paladin National Stalking Advocacy Service. (2020, April 29). Stalking victims reveal horror of lockdown as reports rise. Retrieved from: https://paladinservice.co.uk/stalking-victims-reveal-horror-oflockdown-as-reports-rise/

Sinha, I., Bennett, D., \& Taylor-Robinson, D. C. (2020). Children are being sidelined by COVID-19. The British Medical Journal, 369:m2061. Retrieved from: https://www.bmi.com/content/369/ bmj.m2061

Social Care Institute for Excellence. (2020). Coronavirus (COVID-19) advice for social care: Safeguarding children and families during the COVID-19 crisis. Retrieved from: https://www.scie.org.uk/careproviders/coronavirus-covid-19/safeguarding/children

The Early Action Together Programme. (2020). The Early Action Together ACEs learning network. Royal Society for Public Health. Retrieved from: https://www.rsph.org.uk/our-work/resources/early-actiontogether-learning-network.html

UN News. (2020, April 6). UN chief calls for domestic violence "ceasefire" amid "horrifying global surge." Retrieved from: https://news.un.org/ en/story/2020/04/1061052

Wales Violence Prevention Unit. (2020). Violence Prevention Unit: Working together to prevention violence in Wales. Retrieved from: https:// www.violencepreventionwales.co.uk/

Walton, R., \& Falkner, S. (2020). Policing a pandemic: The challenges of maintaining law and order during the Coronavirus response. Retrieved from: https://policyexchange.org.uk/wp-content/uploads/ Policing-a-Pandemic.pdf

Welsh Government. (2015). Well-being of Future Generations (Wales) Act 2015: The essentials. Retrieved from: https://futuregenerations. wales/wp-content/uploads/2017/02/150623-guide-to-the-fgact-en.pdf

World Health Organization. (2020). The Public Health Approach, WHO Violence Prevention Alliance. Retrieved from: https://www.who.int/ violenceprevention/approach/public_health/en/ 